\title{
Feasibility of MRI in Early Diagnosis of Musculoskeletal Complications of Sickle Cell Disease in Pediatrics
}

\author{
NESREEN MOHEY, M.D. and TAMIR A. HASSAN, M.D. \\ The Department Radiology, Faculty of Medicine, Zagazig University, Egypt
}

\begin{abstract}
Background: Sickle cell disease (SCD) include a group of genetic abnormalities in which there is inheritance of $\mathrm{Hb}$ $\mathrm{S}$ (sickle hemoglobin) from both parents, or $\mathrm{Hb} \mathrm{S}$ from one parent and a gene for beta-thalassemia or an abnormal hemoglobin from the other parent. The most common and the most severe form is sickle cell anemia.

Aim of Study: To evaluate the feasibility of MRI in early detection of musculoskeletal complications of pediatric sickle cell disease (SCD) aiming to discriminate osteomyelitis from infarction.

Patients and Methods: This prospective study included 30 patients ( 21 boys, 9 girls) with a mean age of 5 years proved to have SCD and suspected to have osteomyelitis. All patients underwent X-ray and different sequences MRI.

Results: Persistence of red marrow and multiple bone infarctions were the most common MRI findings followed by osteomyelitis in 8 , chondritis in 7, myositis in 4, septic arthritis in 3 , subperiosteal and soft tissue abscess each in 2 . There was difficulty in discriminating infarction from osteomyelitis

Conclusion: MRI is helpful in early identification of musculoskeletal abnormalities in SCD in pediatrics. Early detection is crucial to initiate treatment to avoid the complication.
\end{abstract}

Key Words: Sickle cell disease - SCD - Bone marrow infarction - Osteomyelitis - Septic arthritis - Subperiosteal abscess.

\section{Introduction}

SICKLE cell disease (SCD) include a group of genetic abnormalities in which there is inheritance of $\mathrm{Hb} \mathrm{S}$ (sickle hemoglobin) from both parents, or $\mathrm{Hb} \mathrm{S}$ from one parent and a gene for beta-thalassemia or an abnormal hemoglobin from the other parent. The most common and the most severe form is sickle cell anemia. $\mathrm{Hb} \mathrm{S}$ can form polymers under deoxygenation conditions and can cause changes in the red blood cells from their usual biconcave disk shape into a crescent or sickle shape

Correspondence to: Dr. Tamir A. Hassan,

E-Mail: tamirhaq@yahoo.com during deoxygenation and upon reoxygenation, the red cell initially resumes their normal configuration, but after repeated attacks of "sickling and unsickling", the red blood cells is permanently damaged and hemolyzes thus causing sickle cell anemia. These abnormalities are the cause of intense clinical expressions of the sickling syndromes. Affected individuals show a wide range of clinical problems resulting from vascular ischemia and obstruction including recurrent pain and progressive infarction. [1-4].

Ischemic complications include painful episodes involving bones and soft tissues, cerebral vascular accidents, acute chest syndrome, priapism, splenic infarction and sequestration and renal dysfunctions. MRI is the superior imaging modality in diagnosing wide range of abnormalities and multisystem affection caused by SCD $[5,6]$ and familiarity of these imaging findings is vital to precisely detect the complications early and initiate proper treatment $\left[^{7},{ }^{8}\right]$.

Bone marrow infarction may have a very similar appearance at MR imaging compared to osteomyelitis as both show areas of high signal on T2weighted and inversion recovery with variable enhancement, so the differentiation of both at MRI is difficult [3]. Soft-tissue abnormalities like edema and abnormal periosteal enhancement, abnormal enhancement of the muscle, fascia, and subcutaneous fat were thought to be a sign of osteomyelitis; but unluckily, the same abnormalities in the soft tissue might also be depicted with infarction [9] .

Plain X-ray, CT and also scintigraphy scans have limited role in such differentiation, as most of the positive signs could be found in both pathologies [10-12]. Other studies mentioned that MRI still the most specific and sensitive imaging modality and mentioned common shared signs e.g. soft tissue and bone marrow edema, the bone 
marrow pattern of enhancement which is one of the major differentiating points as the enhancement pattern with osteomyelitis is usually thick, irregular ring enhancement around a non-enhancing center, whereas infarction usually showed serpiginous long segmental medullary enhancement. Thus it is now far and wide accepted, that MR imaging is the most sensitive and specific imaging tool for early diagnosis of avascular necrosis (AVN) and osteomyelitis than other modalities $[\mathbf{1 1 , 1 3 , 1 4}]$

\section{Aim of work:}

The aim of work is to evaluate the feasibility of MRI in early diagnosis of musculoskeletal complications of SCD in pediatrics aiming to discriminate between osteomyelitis from infarction.

\section{Patients and Methods}

This prospective study included 30 patients (21 boys, 9 girls) proved to have sickle cell disease based on clinical examination and laboratory investigation, their ages ranged between (1-14 years) with a mean age of 5 years. All patients were referred from pediatric and Orthopedic Departments to the Radiodiagnosis and Medical Imaging Department in Tertiary Center. This study was conducted from October 2017 to December 2018 and approval of the medical research ethics committee was obtained. Detailed informed consent was obtained from the legal guardians of all patients.

\section{Inclusion criteria:}

Laboratory proven pediatric SCD patients suspected to have osteomyelitis complaining of pain on ambulation, fever, focal tenderness or redness.

\section{Exclusion criteria:}

- Contraindication to MRI (e.g. incompatible cochlear implants, valves, etc).

- Renal impairment prevents contrast administration.

\section{All the patients underwent:}

- Complete clinical examination.

- Laboratory investigation including complete blood cell count to document anemia, presence of sickled erythrocytes in the peripheral blood smear, differential white blood cell count, reticulocyte percentage, hemoglobin electrophoresis, as well as creatinine and BUN.

All patients were referred to the radiology department for imaging and underwent:

- X-ray of the suspected affected bone (AP and lateral views).
- MRI of the suspected bone to detect musculoskeletal abnormalities in this sickler patient and trying to exclude osteomyelitis. All patients underwent MRI using 1 .5T MRI unit (GE medical system, HDE 1.5T, USA), the choice of the coil depends on the part examined and standard axial, coronal, sagittal fast spin-echo T1WI, T2WI, STIR sequences were used after obtaining gradient spoiled scout view. Contrast-enhanced MRI (CE-MRI) scans were done to all patients after the standard pre-contrast sequences; including coronal, oblique axial and sagittal fat suppressed T1WFSE. Contrast enhanced sequences were obtained after intravenous injection of 0.1 $\mathrm{mmol} / \mathrm{kg}$ of gadolinium based contrast; magnevist (gadolinium diethylene-triaminepenta-acetic acid (Gd-DTPA); Berlex, Montvale, NJ). Oral sedation was given in 21 patients and was under the responsibility of the anesthesia department and was included in separate consent.

\section{Image interpretation:}

Analyses for each MRI was done by 2 independent musculoskeletal experienced radiologists searching for musculoskeletal abnormalities caused by sickle cell disease on dedicated workstation to answer the following questions:

1- Is there any infarction or infection?

2- Where is the infection?

3- Bone marrow enhancement type.

4- Extension of the infection

5- Are there drainable collection ?

6-Associated musculoskeletal complications.

In case of controversy in the MRI findings, conjoint meeting was done between the 3 radiologists and solved in consensus.

\section{Results}

This study included 30 patients proved by laboratory to have SCD, boys (21 patients, 70\%) were affected more than girls (9 patients, 30\%) and their ages ranged between (1-14 years) with a mean age of 5 years.

Persistence of red marrow (100\%), (Figs. 1-7) and multiple bone infarctions $(90 \%)$ were the most common MRI findings. Chondritis occurred in 7 patients $(23.3 \%)$, myositis in $4(13.3 \%)$, septic arthritis in $3(10 \%)$, subperiosteal and soft tissue abscess each in $2(6.7 \%)$ and both underwent drainage (Table 1). 
Eight cases have multiple bone infarction and coexisting osteomyelitis and there was difficulty in discriminating infarction from osteomyelitis but it was confirmed by clinical, laboratory evaluation and radiological follow-up that suggested the possibility of infective process.

All patients did X-ray before MRI and the Xray detects SCD bony abnormalities only in 2 patients showing metaphyseal band (Fig. 7) while MRI was able to detect the early abnormality in all patients (Table 2).

MRI detected musculoskeletal abnormalities in the 30 patents, femur was the most affected bone $(40 \%)$ followed by the tibia (33.3\%) (Table 3 ).

Table (1): MRI findings in the 30 patients.

\begin{tabular}{lcc}
\hline MRI abnormality & $\begin{array}{c}\text { No. of } \\
\text { patients }\end{array}$ \\
\hline 1- Persistent red marrow & 30 & 100 \\
2- Bone infarction & 27 & 90 \\
3- Osteomyelitis with existing bone infarction & 8 & 26.7 \\
4- Chondritis & 7 & 23.3 \\
5- Myositis & 4 & 13.3 \\
6- Septic arthritis & 3 & 10 \\
7- Subperiosteal abscess & 2 & 6.7 \\
8- Soft tissue abscess & 2 & 6.7 \\
\hline
\end{tabular}

Table (2): Correlation between X-ray and MRI in early detection.

\begin{tabular}{lcc}
\hline $\begin{array}{l}\text { Radiological } \\
\text { changes }\end{array}$ & MRI & X-ray \\
\hline 1- Positive & 30 & 2 \\
2- Negative & 0 & 28 \\
\hline
\end{tabular}

Table (3): Location of bones affected.

\begin{tabular}{lcl}
\hline Site of the bone affected & No. of patients & $\%$ \\
\hline 1- Femur & 12 & 40 \\
2- Tibia & 10 & 33.3 \\
3- Humerus & 3 & 10 \\
4- Pelvis & 2 & 6.7 \\
5- Radius & 2 & 6.7 \\
6- Thorax & 1 & 3.3 \\
\hline Total & 30 & 100 \\
\hline
\end{tabular}

N.B: Laterality of the bone infarction has to be considered.
The 8 patients with osteomyelitis were 3 in the femur while the tibia, humerus, radius pelvis, thorax (Fig. 2) each in 1 patient (Table 4).

Osteomyelitis in the 8 patients started at the metaphysis and spread to the epiphyses and the joints in 3 patients $(37.5 \%)$ and to the muscles in 4 patients $(50 \%)$, (Table 5, Figs. 3-6).

Bone marrow enhancement was heterogeneous in 25 patients $(83.3 \%)$ and diminished compared with normal bone marrow in 5 patients $(16.7 \%)$ and these 5 patients were among the osteomyelitis group patients (Table 6).

Table (4): Location of osteomyelitis in 8 patients.

\begin{tabular}{lcc}
\hline $\begin{array}{l}\text { Site of the bone } \\
\text { affected }\end{array}$ & $\begin{array}{c}\text { No. of } \\
\text { patients }\end{array}$ & $\%$ \\
\hline 1- Femur & 3 & 37.5 \\
2- Tibia & 1 & 12.5 \\
3- Humerus & 1 & 12.5 \\
4- Pelvis & 1 & 12.5 \\
5- Radius & 1 & 12.5 \\
6- Thorax & 1 & 12.5 \\
\hline Total & 8 & 100 \\
\hline
\end{tabular}

Table (5): Sites of early osteomyelitis and its extension in the 8 patients.

\begin{tabular}{lcc}
\hline Sites of affection & $\begin{array}{c}\text { No. of } \\
\text { patients }\end{array}$ & $\%$ \\
\hline 1- Metaphyseal & 8 & 100 \\
2- Extension to the epiphyses & 3 & 37.5 \\
3- Extension to the joint & 3 & 37.5 \\
4- Extension to the muscles (myositis) & 4 & 50 \\
\hline
\end{tabular}

Table (6): Marrow enhancement pattern of affected bone in MRI

\begin{tabular}{llc}
\hline Type of enhancement & $\begin{array}{l}\text { No. of } \\
\text { patients }\end{array}$ & $\%$ \\
\hline \hline 1- Heterogeneous & 25 & 83.3 \\
2- Diminished compared & 5 & 16.7 \\
with normal marrow & & \\
\hline
\end{tabular}



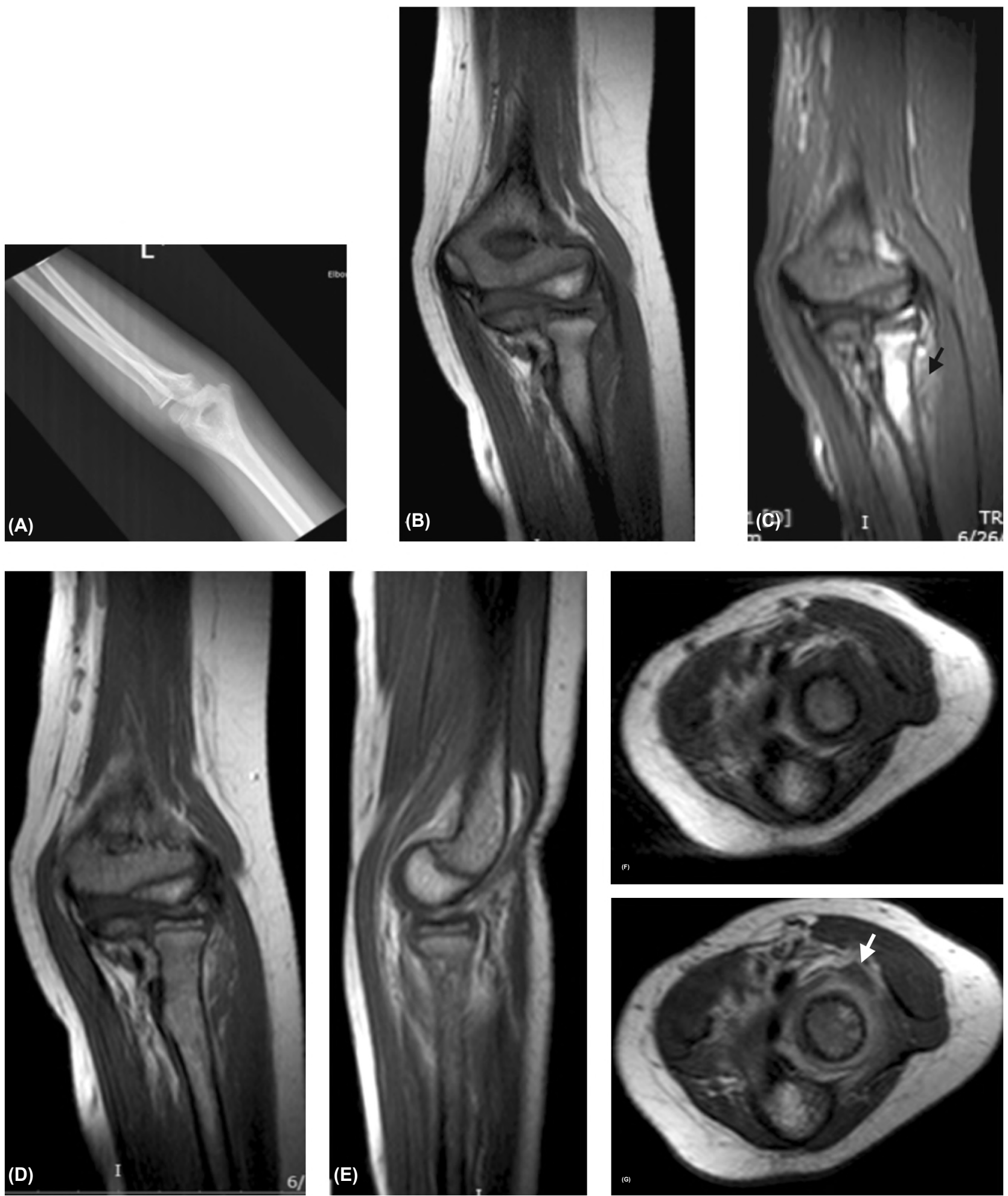

Fig. (1): Boy 6 years with SCD showing normal xray (A). Different sequences MRI (B,C,D are pre-contrast, E,FG are post contrast) show persistent red marrow, and bone infarction in the radius (red arrow in $\mathrm{C}$ ) with heterogeneous marrow and periosteal enhancement (arrow in G). 


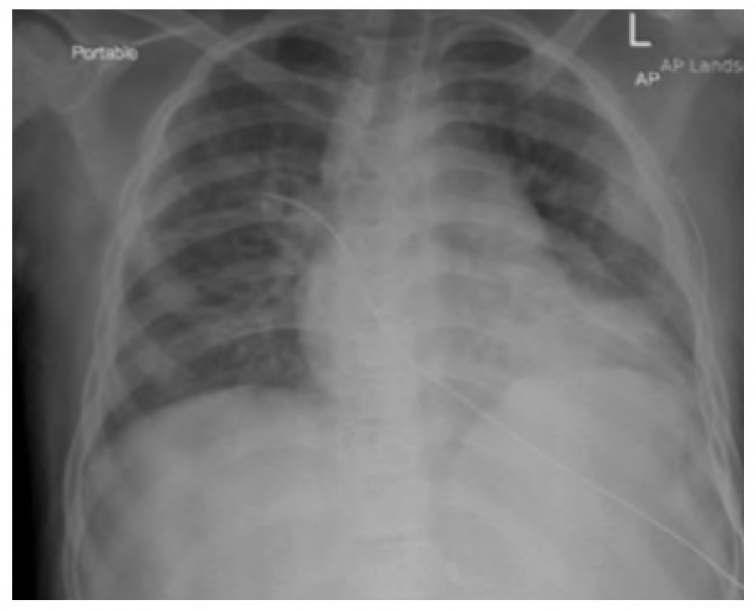

(A)

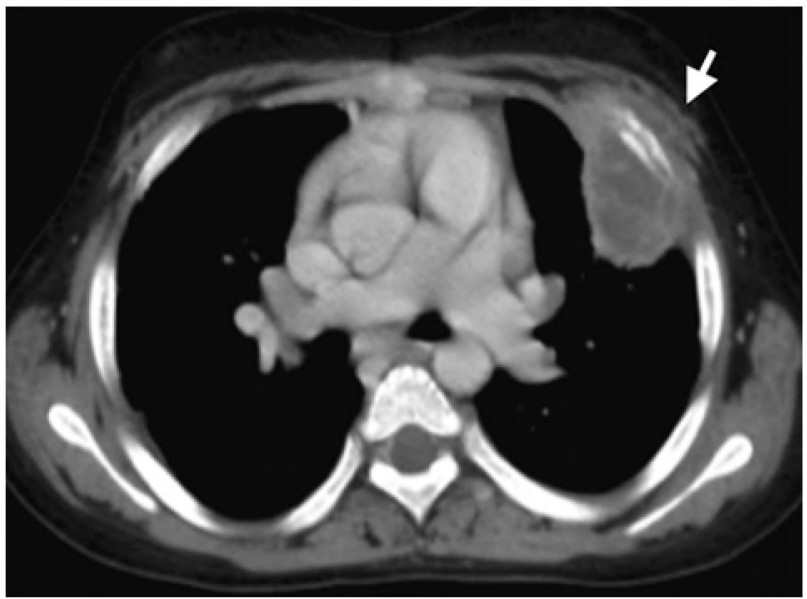

(C)

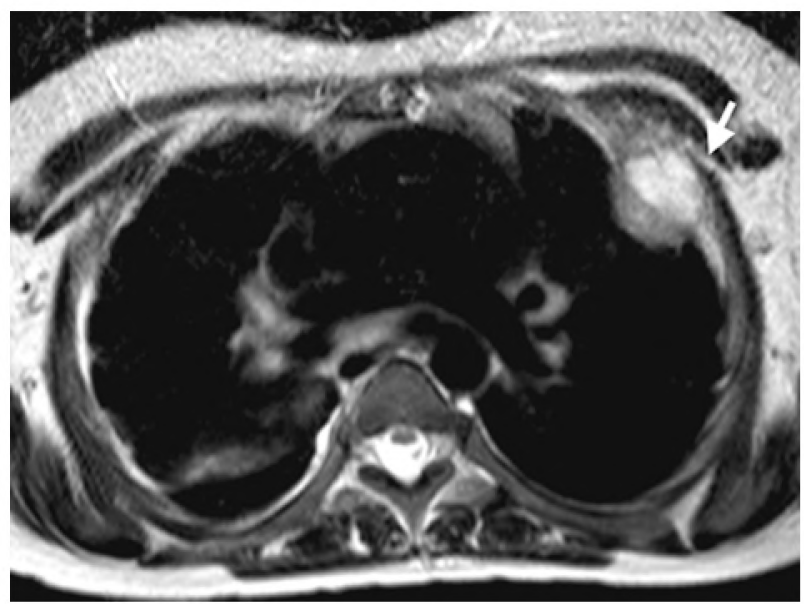

(E)

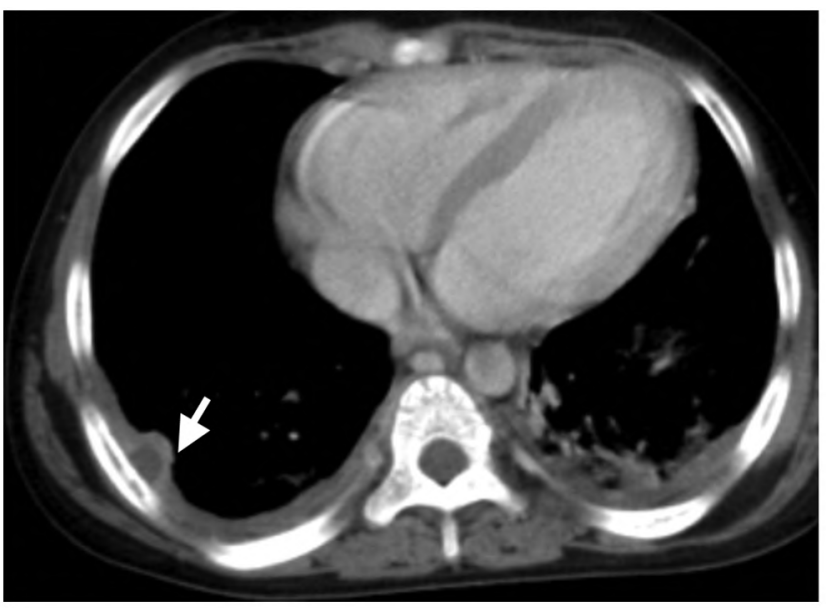

(B)

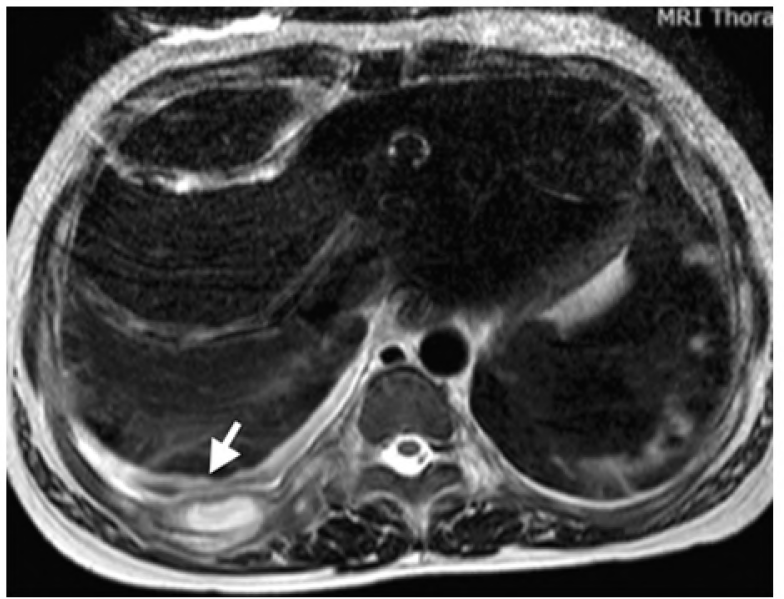

(D)

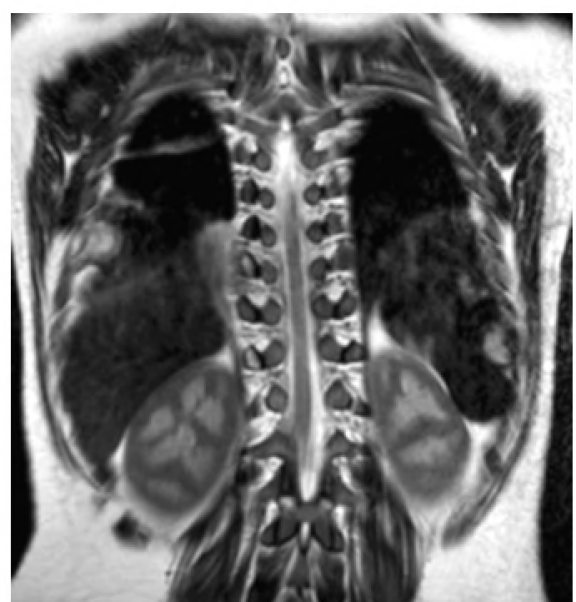

(F)

Fig. (2): Boy 9 years with SCD showing normal xray (A). CT (B, C post contrast) and different sequences MRI (D, E, F) show persistent red marrow, and rib osteomyelitis and chest wall subperiosteal abscesses (red arrows in B-E). 


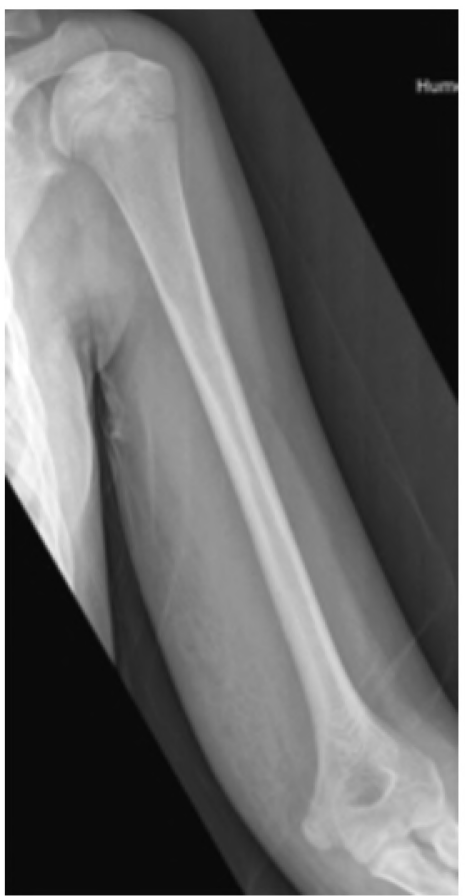

(A)

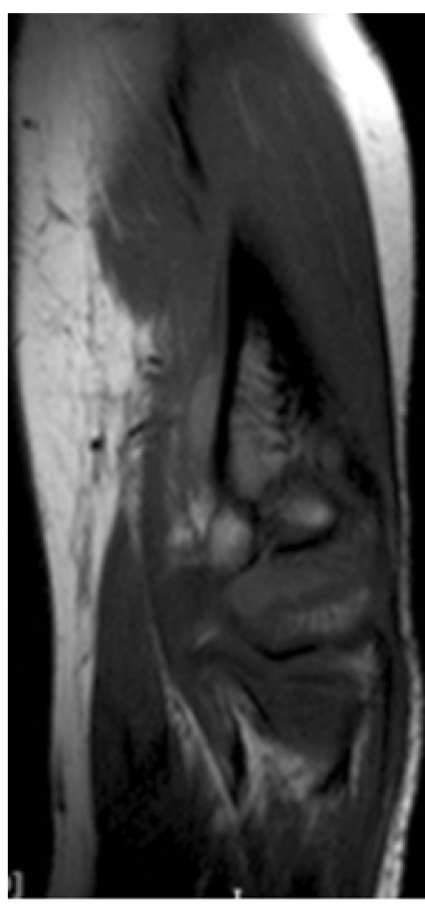

(C)

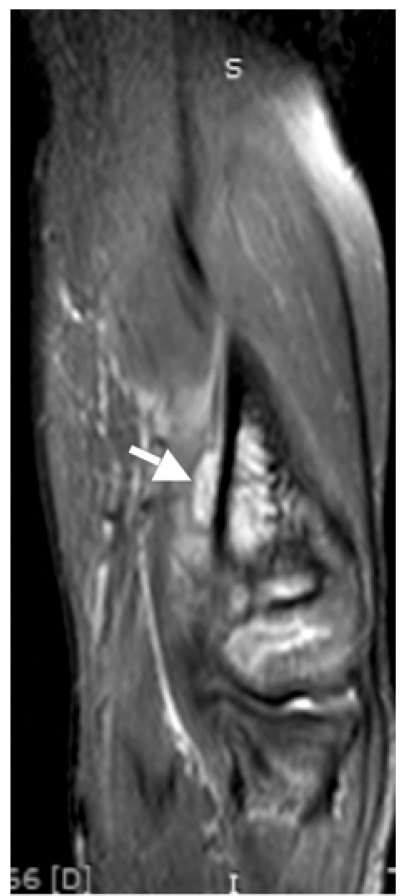

(B)
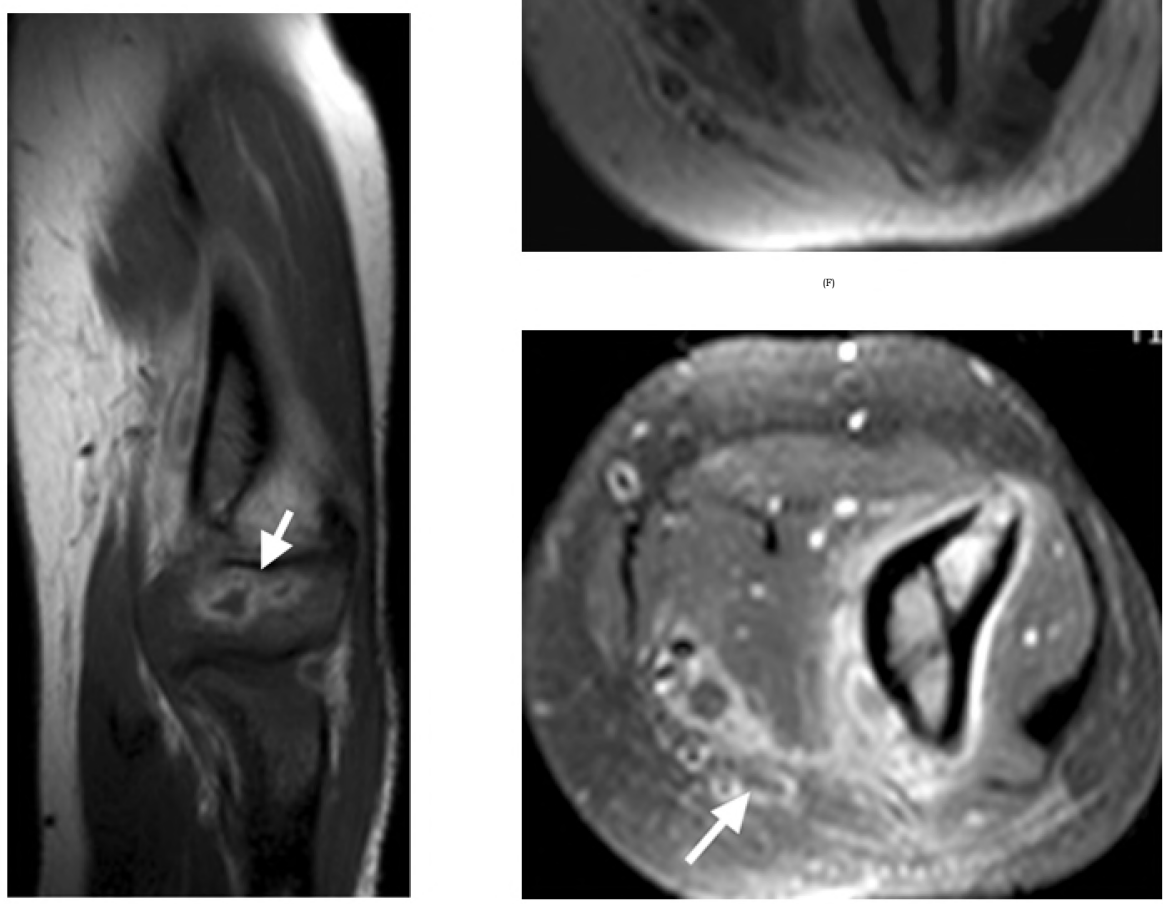

Fig. (3): Boy 7 years with SCD with final diagnosis of osteomyelitis distal humerus. Normal X-ray (A). Different sequences MRI (precontrast series B-G, contrast series are C-G) show persistent red marrow, bone infarction showing serpegenious appearance (red arrow in D), subperiosteal abscess (blue arrow in B), and myositis (yellow arrow in G). 


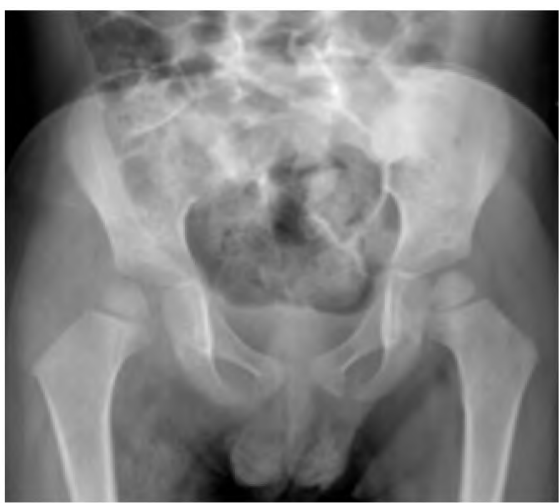

(A)

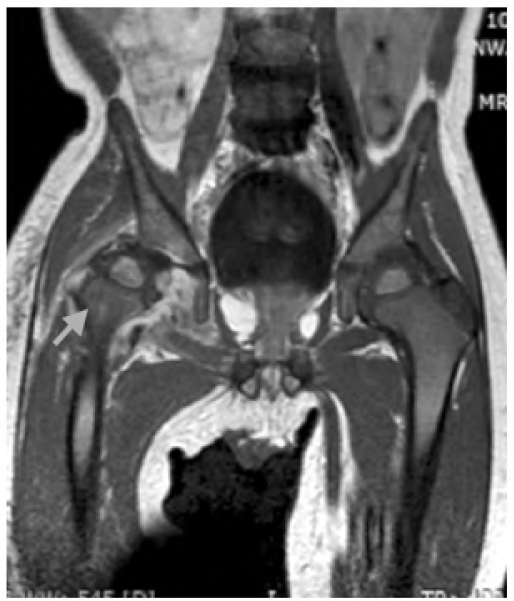

(D)

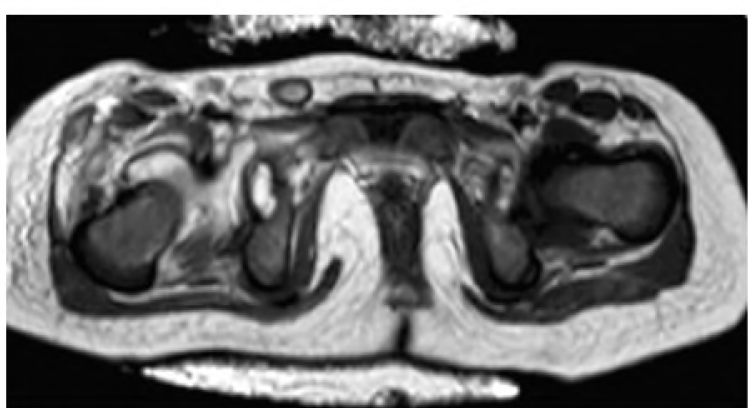

(G)

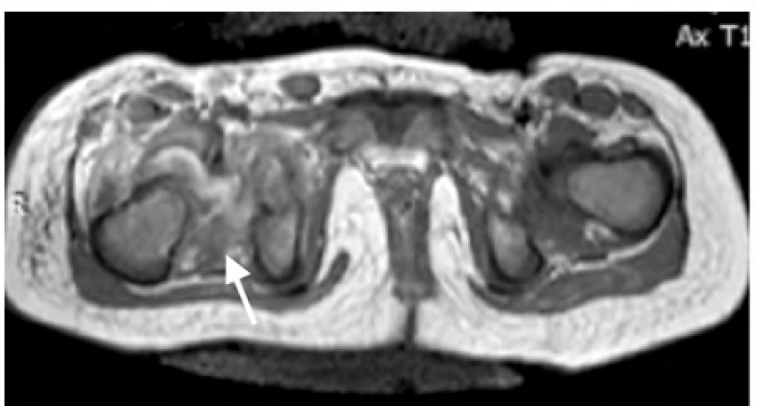

(I)

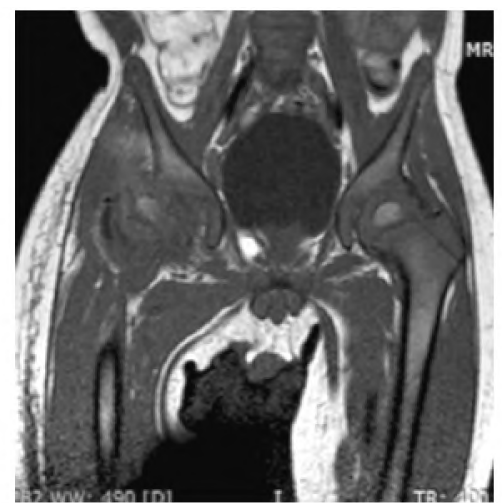

(B)

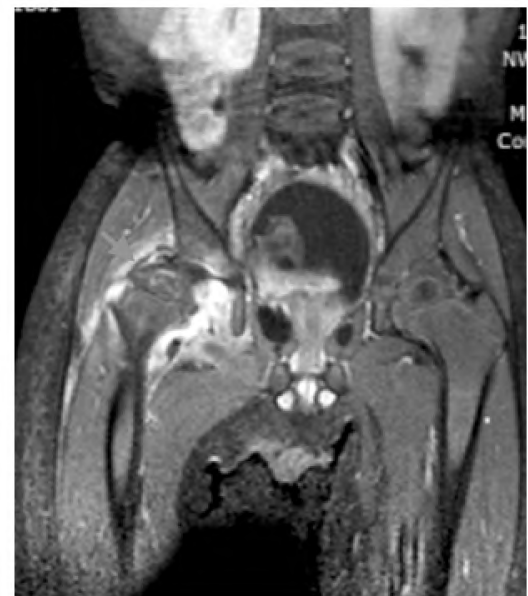

(E)

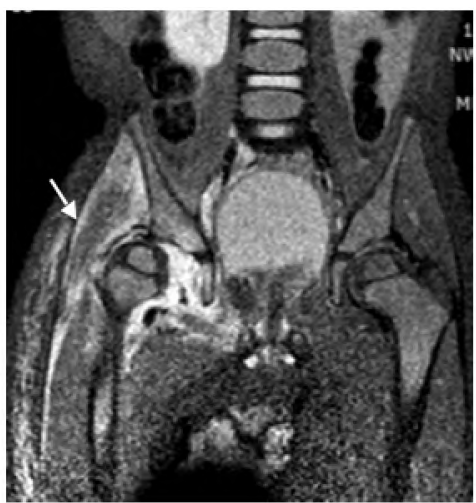

(C)

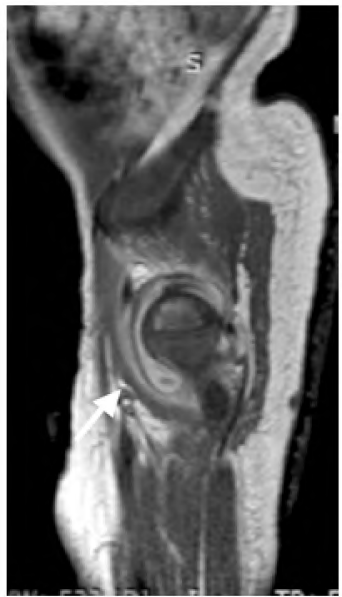

(F)

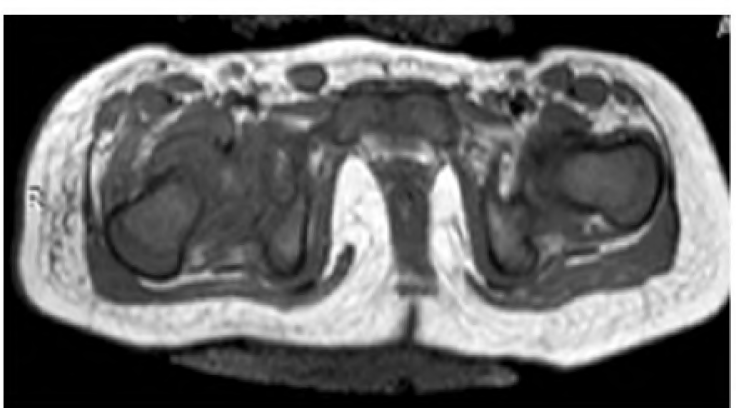

(H)

Fig. (4): Boy 3 years old with SCD with final diagnosis of osteomyelitis right hip. Normal X-ray (A). Different series MRI (B,C,G,H pre-contrast, D,E,F,H,I contrast series) show persistent red marrow, osteomyelitis showing diminished enhancement (green arrow in D), heterogeneous in T1 fat sat (red arrow), septic arthritis (yellow arrow in F) and myositis (white arrow in I) 

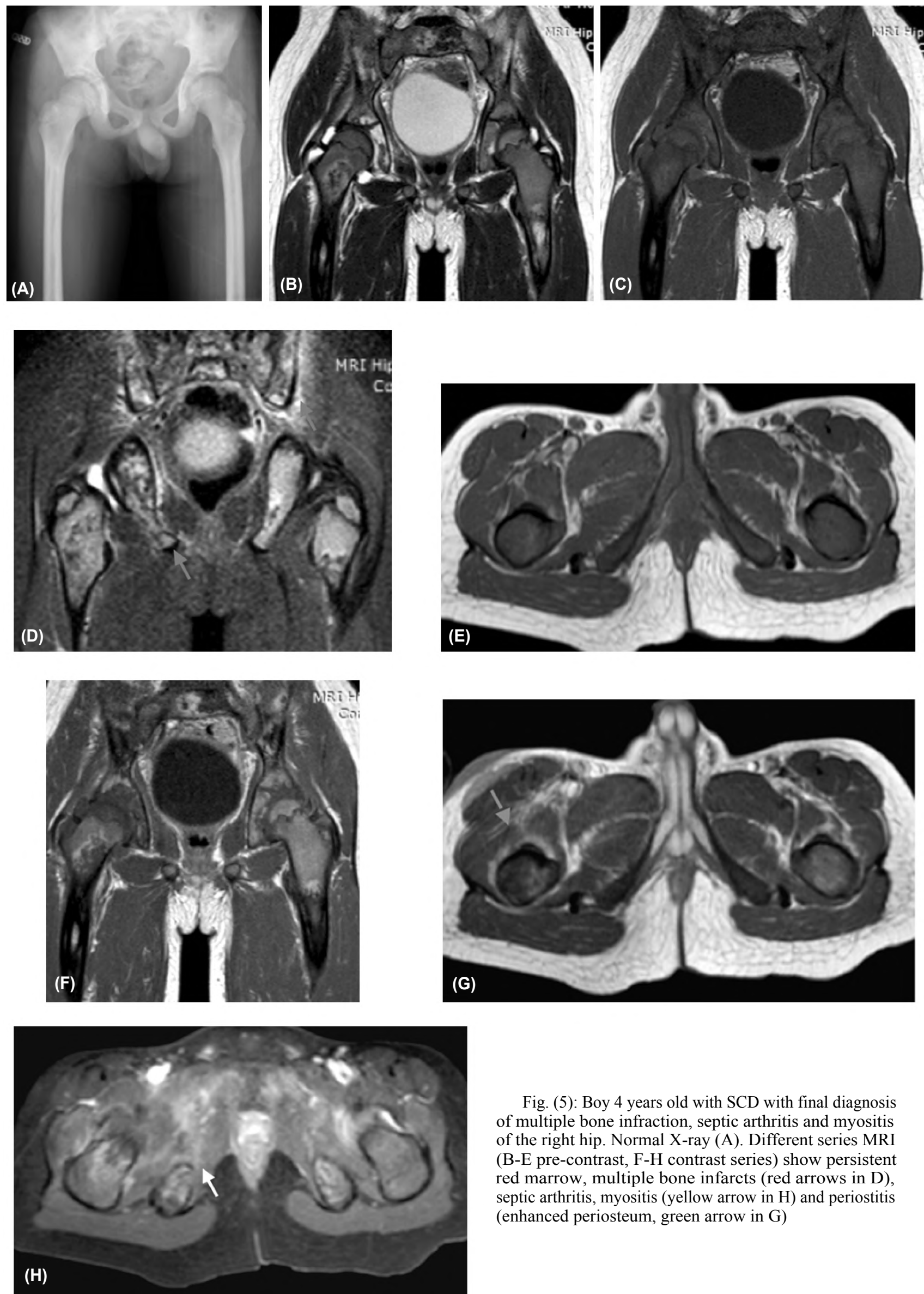

Fig. (5): Boy 4 years old with SCD with final diagnosis of multiple bone infraction, septic arthritis and myositis of the right hip. Normal X-ray (A). Different series MRI (B-E pre-contrast, F-H contrast series) show persistent red marrow, multiple bone infarcts (red arrows in D), septic arthritis, myositis (yellow arrow in $\mathrm{H}$ ) and periostitis (enhanced periosteum, green arrow in $\mathrm{G}$ ) 


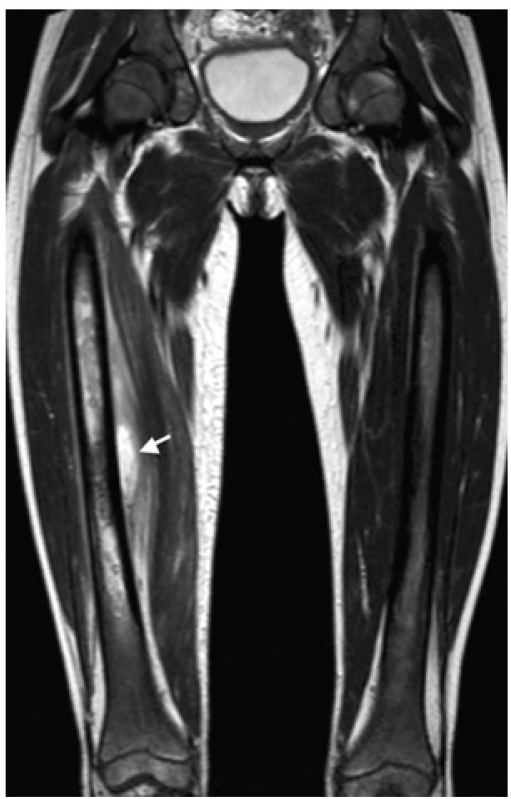

(A)

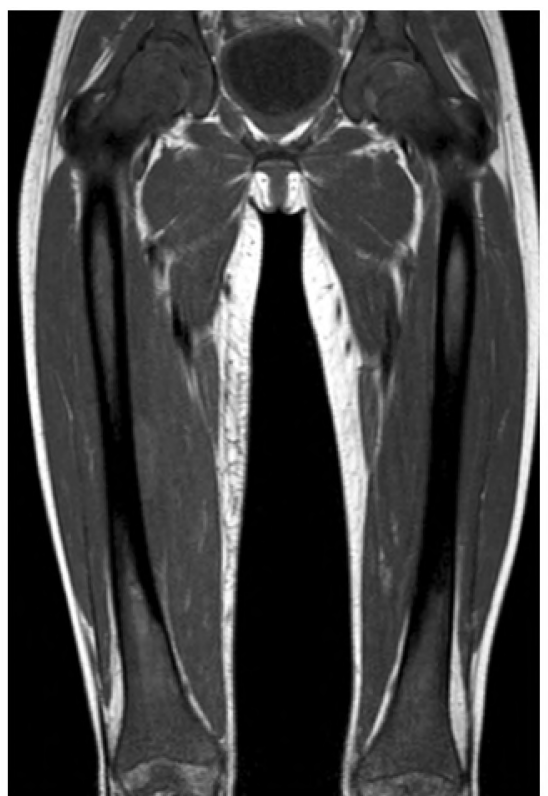

(B)

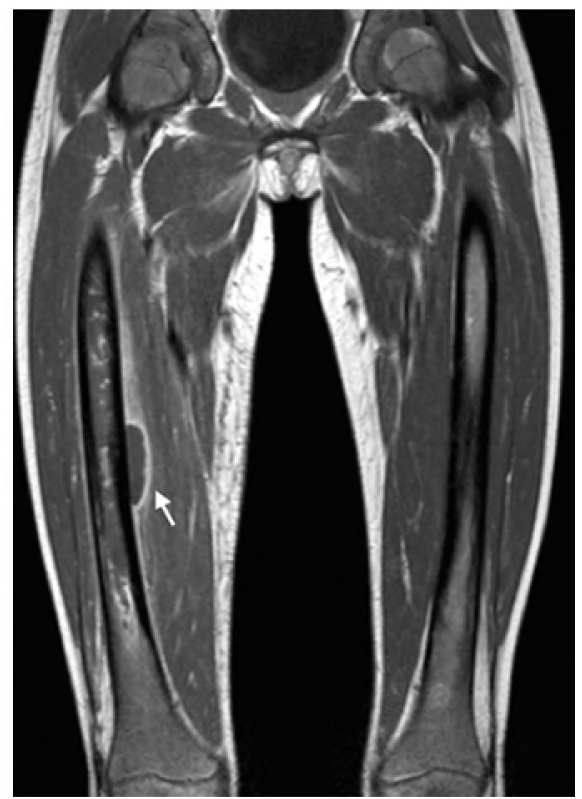

(C)

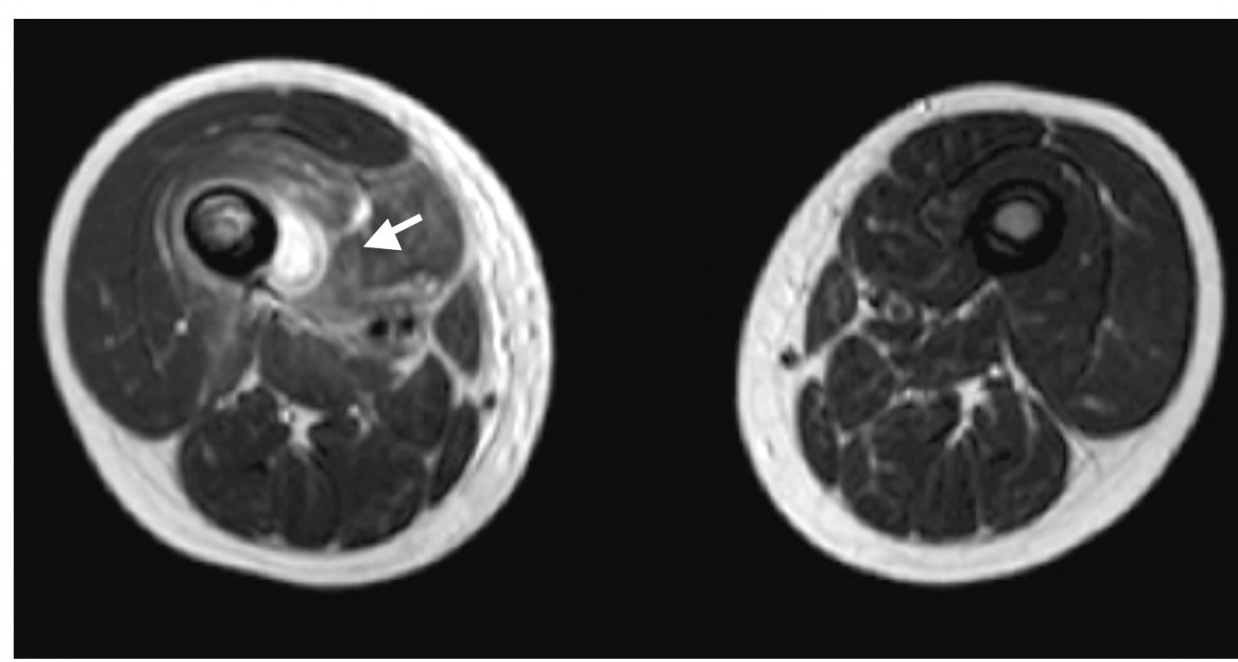

(D)

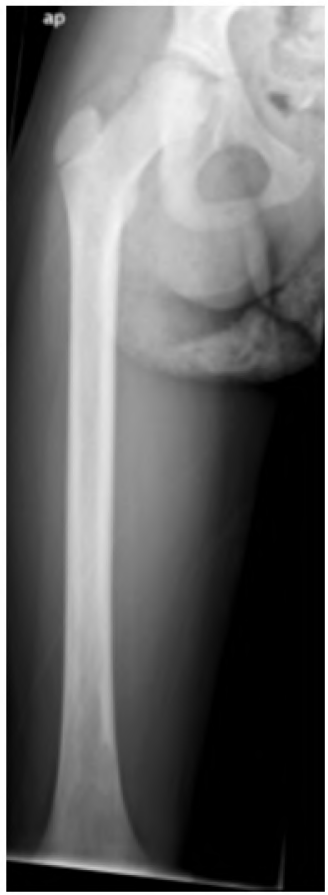

(E)

Fig. (6): Boy 5 years old with SCD with final diagnosis of right femoral osteomyelitis and subperiosteal abscess. Normal Xray (E). Different series MRI (A-B pre-contrast, C-D contrast series) show persistent red marrow, bone infarcts with subperiosteal abscess (yellow arrows in A,C,D) and myositis, heterogeneous marrow enhancement; combination was in favor of osteomyelitis 

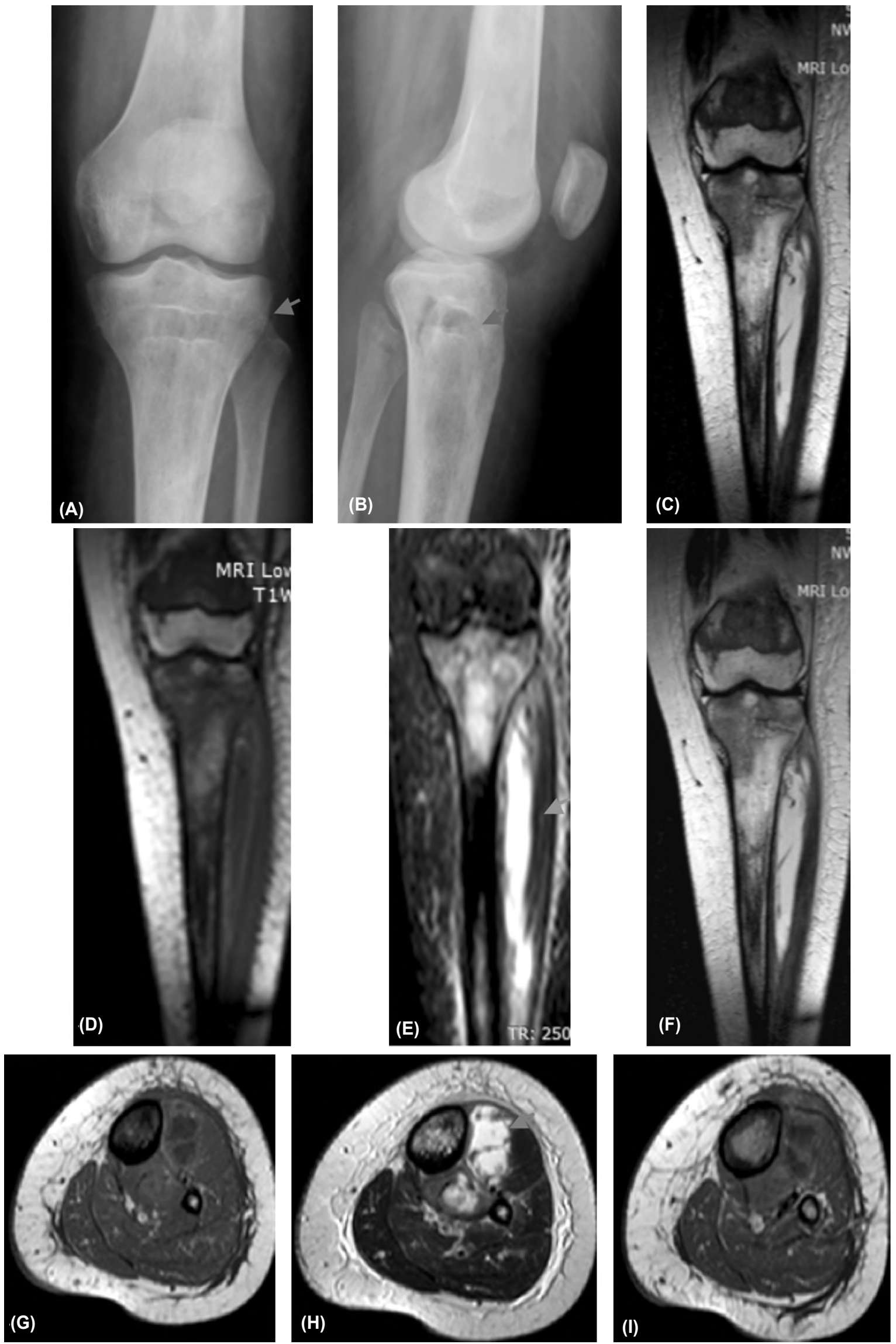

Fig. (7): Girl 6 years old with SCD with final diagnosis of right tibial osteomyelitis and subperiosteal abscess. X-ray (A,B) show metaphyseal band (blue arrow in A,B). Different series MRI (C,D pre-contrast, E,F contrast coronal series, G,H axial pre contrast, I axial post contrast) show bone infarction with large subperiosteal and intramuscular abscess (red arrows in $(\mathrm{H})$ and myositis, heterogeneous marrow enhancement; combination was in favor of osteomyelitis 


\section{Discussion}

Acute, painful vaso-occlusive crises are the most common, and earliest, clinical manifestations of SCA. Half of all patients with SCA experience a painful crisis by 4.9 years of age. The pain in the vaso-occlusive crisis frequently described as bone pain, though crises may affect any organ and usually caused by tissue ischemia secondary to microvascular occlusion. Vaso-occlusive crises frequently noticeable in young children as dactylitis which is a painful swelling of the fingers, toes, hands and feet. Other adverse outcomes in SCA include osteomyelitis, osteonecrosis, acute chest syndrome, stroke, papillary necrosis, renal insufficiency splenic infarct and splenic sequestration [3].

Proving or disproving of acute osteomyelitis is early required for good outcome, as delayed treatment markedly increases the complications of osteomyelitis as septic arthritis, pyomyositis, subperiosteal abscess, deep vein thrombosis, destruction of the epiphyses with consequent permanent deformity, septicemia, chronic osteomyelitis, multiple organ system failure and death $[\mathbf{1 5 , 1 6 ]}$.

Pediatrics with bone infection frequently complain of fever, ambulation pain, local tenderness and occasionally redness that worsens on few days. Elevated white blood cell count usually found in only $36 \%$ of children, but if both the $\mathrm{C}$ reactive protein and ESR (erythrocyte sedimentation rate) values are abnormally increased, the sensitivity for infection reaches $98 \%$ [17].

The present study included 30 patients known to have sickle cell disease, boys (70\%) were affected more than girls (30\%), with a mean age of 5 years in agreement with $[3,10,15]$ studies who mentioned similar sex and age group incidence.

Current study reveals that persistence of red marrow (100\%) and multiple bone infarctions (90\%) were the most common MRI findings in agreement with $[3,10,15,16]$. Resnick et al., [16] reported that the skeletal system of SCD patients contains congested, cellular marrow all over most of the skeletal system causing bone infarction that classically occurs in the epiphysis and the medullary cavity usually seen in every marrow-containing bone. The underlying cause of pain crises in SCA usually caused by bone marrow infarction. Ischemia promptly causes pain, even before infarction is established; hence, early radiographs obtained during pain crises often are negative [19].
In the current study, Chondritis occurred in 7 patients $(23.3 \%)$, myositis in $4(13.3 \%)$, septic arthritis in $3(10 \%)$, subperiosteal and soft tissue abscess each in $2(6.7 \%)$ patients and underwent drainage in agreement with $[3,15]$ who explained the occurrence of these complications by the communication between the epiphyseal and metaphyseal vessels in the first 18 months of life resulting in straight extension of metaphyseal infections into the epiphysis. Epiphyseal extension can result in epiphyseal cartilage destruction and the 2ry ossification center and may contributes to the increased incidence of septic arthritis in this age [20,21].

Septic arthritis in the present study was observed in 3 patients $(10 \%)$ and may be explained in conjunction with Khedr et al., [3] who reported that septic arthritis is less frequent than osteomyelitis and usually demonstrate bony, articular cartilage erosion, synovial thickening as well as enhancement, bone marrow edema and joint effusion usually in the large joints. It is supposed that sickling of synovial capillaries might rise the susceptibility to infarction and diminish the response to antibiotic treatment.

Subperiosteal abscess was found in the current study in 2 patients $(6.7 \%)$ in agreement with Jaramillo et al., [15] who explained its occurrence that the periosteum of the growing skeleton has 2 layers: The fibrous periosteum which is strong superficial layer and the cambium of the periosteum which is an inner, highly vascular layer that has a role in membranous bone growth [22]. An infection can reach the subperiosteal space, possibly from the focus in the metaphysis or probably by direct seeding [23], and consequently propagate through the highly vascular cambium [24]. The fibrous layer of the periosteum thus separated easily from the underlying bone by pus so a subperiosteal abscess develop.

In the current study, 8 cases had osteomyelitis on the background of multiple bone infarction, and there was difficulty in differentiating infarction from osteomyelitis but this was highly suggested by clinical, laboratory results and radiological follow up that suggested the possibility of infective process rather than infarction in agreement with $[3,10,15]$ results. Jaramillo et al., $[15]$ reported that there is great difficulty in differentiating infection and infarction (vaso-occlusive crisis) in SCD. Non sickler children with osteomyelitis usually present with a longer duration of pain, swelling and fever than children with SCD and vaso-occlusive crises. Vaso-occlusive crisis is more probable if more than one site is involved [25]. The chief imaging problem 
is that infarction and infection can coincide thus their imaging findings can overlap. One recent study [26] tried to discriminate infection from infarction using T1-weighted images fat-suppressed sequence where stagnant blood in the infarction display high signal while infected, edematous bone marrow demonstrate low signal. In the current study differentiation was not possible, because osteomyelitis developed in areas of infarction thus we depend on combination of clinical evaluation, laboratory results and follow-up.

It is well established that infection can cause bone ischemia even in children without SCD [27]. Another great challenge is that infarction is nearly 50 times more frequent than infection in patients with SCD [25] which is also found in our results as bone infarction was seen in all cases while osteomyelitis in $26.7 \%$ of cases.

Evaluation by Scintigraphy usually based on a combination of bone marrow scanning utilizing Tc99m sulfur colloid and bone scanning using Tc99m methylene diphosphonate [20]. In the series by Skagg et al., [20] infections showed increased uptake on bone scans but regular activity on marrow scans whereas infarcts showed no uptake on the marrow scans. Though the authors succeeded in diagnosing 4 cases of osteomyelitis, but the technique assumes that infarction and infection do not coexist (which is not the usually), also the combination of both bone and marrow scanning yields considerable radiation dose [28]

We didn't include scintigraphic evaluation in our study (although available in the hospital) because the radiation dose (organ-specific absorbed dose) is specifically higher than $10 \mathrm{mGy}$ for the bone marrow and $50 \mathrm{mGy}$ for the urinary bladder [29] because of which all legal guardians will not approve to do the test for their kids.

To our limited knowledge, there is no reference standard for diagnosing SCD related osteomyelitis, and even the culture of biopsy specimens is not totally reliable [3]. On MR imaging, bone infarctions usually diaphyseal and the edema is predominantly intramedullary, whereas osteomyelitis usually causes circumferential edema and affects the bones and soft tissues almost equally [10] in agreement with our MRI findings.

All patients did X-ray before doing MRI and the X-ray detects SCD bony abnormalities only in 2 patients showing metaphyseal band while MRI was able to detect the early abnormality in all patients in agreement with Jaramillo et al., [15] who mentioned that the diagnostic sensitivity of conventional radiographs in acute osteomyelitis of pediatrics is less than $20 \%$ and may be useful in directing the subsequent imaging evaluation and exclude other different condition such as tumor or trauma with similar symptoms thus MRI usually highly recommended for evaluation of a child with suspected osteomyelitis [30].

The MRI sequences should include a combination of T1-weighted images and STIR images in the sagittal or coronal plane, axial fat-suppressed $\mathrm{T} 2$-weighted images, and post gadolinium fatsuppressed T1-weighted images which was the adopted technique in the current study.

Among the 30 patients, the femur was the most affected bone (40\%) followed by the tibia (33.3\%). Osteomyelitis was found in 8 patients, 3 of them was found in the femur while the tibia, humerus, radius, pelvis, thorax each in 1 patient in agreement with [15], who mentioned that $75 \%$ of the infections in children occur in the lower extremities, with the femur affection in (27\%), tibia (26\%), pelvis (9\%) occurrence.

Osteomyelitis started in the metaphysis in the 8 patients and spread to the epiphyses and the joints in 3 patients $(37.5 \%)$ and to the muscles in 4 patients (50\%) in agreement with [15] who mentioned that the metaphysis is the primary site of infections because of its vascular characteristics and in the first 18 months of life the communication between epiphyseal and metaphyseal vessels may result in direct progression of metaphyseal infections into the epiphysis.

Bone marrow enhancement was heterogeneous in 25 patients $(83.3 \%)$ and diminished compared with normal bone marrow in 5 patients $(16.7 \%)$ and these 5 patients were among the osteomyelitis group patients in agreement with Jaramillo et al, [15] who reported that the area of bone infection show slow signal of the bone marrow on $\mathrm{T} 1$ weighted images (T1WI) (compared with the adjacent muscle) and high signal on T2- weighted or STIR images. On fat-suppressed T1WI post contrast, bone infection frequently seen as an area of increased enhancement relative to the adjacent normal marrow. However, enhancement of the bone marrow can be diminished or heterogeneous compared with normal marrow. Ischemia within the areas of infected bone marrow may show less enhancement than normal bone marrow or no enhancement on contrast-enhanced MR images [31-32], which is corresponding to the "cold bone scan" seen on scintigraphy [33]. Decreased enhancement of the bone marrow possibly multifactorial, 
may be related to vascular thrombosis, increased intramedullary pressure, and damage of the blood supply to the periosteum and recognition of diminished bone marrow enhancement is significant; as it signifies increased severity of the disease and higher risk for consequent complications [33]

This study has several limitations first is small number of patients, second is narrow selection criteria as we include only laboratory proven pediatrics with SCD having good renal functions in order to do the MRI with contrast which may represent bias as patients with SCD may have renal papillary necrosis and failure preventing contrast administration.

\section{Conclusion:}

MRI is a very helpful modality in early identification of musculoskeletal abnormalities in sickle cell disease in pediatrics, however MRI faced difficulty in distinguishing acute osteomyelitis from bone infarct alone and should be aided by clinical examination, laboratory findings and follow-up. Early detection is crucial to initiate early treatment to avoid the complication.

\section{References}

1- BOOKCHIN R.M. and LEW V.L.: Pathophysiology of sickle cell anemia. Hematol. Oncol. Clin. North. Am., 10: 1241-53, 1996.

2- BALLAS S.K.: Sickle cell disease: Clinical management. Baillieres. Clin. Haematol., 11: 185-214, 1998.

3- SHERIF A. KHEDR, MOHAMED A. HASSAAN, AMRO A. SHABANA, AYMAN H. GABALLAH and DOHA A. MOKHTAR.: Musculoskeletal manifestations of sickle cell disease, diagnosis with whole body MRI. The Egyptian Journal of Radiology and Nuclear Medicine, 43: 77-84, 2012.

4- LANE P.A.: Sickle cell disease. Pediatr. Clin. North. Am., 43: 639-64, 1996.

5- DAVIS C.J., MOSTOFI F.K. and SESTERHENN I.A. Renal medullary carcinoma: The seventh sickle cell nephropathy. Am. J. Surg. Pathol., 19: 1-11, 1995.

6- ALUOCH J.R.: Higher resistance to Plasmodium falciparum infection in patients with homozygous sickle cell disease in western Kenya. N. Engl. J. Med., 317: 781-7, 1997.

7- WETHERS D.L.: Sickle cell disease in childhood. I. Laboratory diagnosis, pathophysiology, and health maintenance. Am. Fam. Phys., 62: 1013-20, 2000.

8- BALLAS S.K. and MOHANDAS N.: Pathophysiology of vaso-occlusion. Hematol. Oncol. Clin. North. Am., 10: 1221-39, 1996.

9- ALMEIDA A, and ROBERTS I.: Bone involvement in sickle cell disease. Br. J. Haematol., 129: 482-90, 2005.

10- MAHMOUD AGHA, AHMED FATHY EID and MAHA SALLAM.: Sickle cell anemia: Imaging from head to toe.
The Egyptian Journal of Radiology and Nuclear Medicine, 44, 547-561, 2013.

11- EJINDU VIVIAN C., HINE ANDREW L., MASHAYEKHI MOHAMMAD, SHORVON PHILIP J. and MISRA RAKESH R.: Musculoskeletal manifestations of sickle cell disease. Radio Graphics, 7: 1005-21, 2007.

12- BAHEBECK J., ATANGANA R., TECHA A., MONNY LOBE M., SOSSO M. and HOFFMEYER P.: Relative rates and features of musculoskeletal complications in adult sicklers. Acta. Orthop. Belg., 70: 107-11, 2004.

13- LOVE C. and PALESTRO C.J.: Radionuclide imaging of infection. J. Nucl. Med. Technol., 32: 47-57, 2004.

14- BLACKSIN1 MARCIA F., FINZEL2 KATHLEEN C. and BENEVENIA JOSEPH.: Osteomyelitis originating in and around bone infarcts. AJR. Am. J. Roentgenol., 176 (2): 38, 2001.

15- DIEGO JARAMILLO, JOHN P. DORMANS, JORGE DELGADO, TAL LAOR and JOSEPH W. St. GEME III. Hematogenous Osteomyelitis in Infants and Children: Imaging of a Changing Disease. Radiology, 283: (3): 629643, 2017.

16- PARSCH K. and NADE S.: Infections of bones and joints. In: Benson M., Fixsen J., Macnicol M., Prarsch K., eds. Children's orthopaedics and fractures. ${ }^{2}$ ed. London, England: Springer, 135-159, 2010.

17- YEO A. and RAMACHANDRAN M.: Acute haematogenous osteomyelitis in children. BMJ, 348: g 66, 2014.

18- RESNICK D.: Hemoglobinopathies and other anemias. In: Resnick D., editor. Diagnosis of bone and joint disorders. Philadelphia, PA: Saunders, p. 2146-87, 2002.

19-JEAN-BAPTISTE G. and De CEULAER K.: Osteoarticular disorders of hematological origin. Baillieres. Best. Pract. Res. Clin. Rheumatol., 14: 307-23, 2000.

20- SKAGGS D.L., KIM S.K., GREENE N.W., HARRIS D. and MILLER J.H.: Differentiation between bone infarction and acute osteomyelitis in children with sickle-cell disease with use of sequential radionuclide bone marrow and bone scans. J. Bone. Joint. Surg. Am., 83-A: 1810-13, 2001.

21- PIEHL F.C., DAVIS R.J. and PRUGH S.I.: Osteomyelitis in sickle cell disease. J. Pediatr. Orthop., 13: 225-7, 1993.

22- FREY S.P., JANSEN H., DOHT S., FILGUEIRA L. and ZELLWEGER R.: Immunohistochemical and molecular characterization of the human periosteum. Sci. World. J., 341078, 2013.

23- LABBÉ J.L., PERES O., LECLAIR O., et al.: Acute osteomyelitis in children: The pathogens is revisited? Orthop. Traumatol. Surg. Res., 96 (3): 268-275, 2010.

24- UNKILA-KALLIO L., KALLIO M.J. and PELTOLA H.: Acute haematogenous osteomyelitis in children in Finland. Finnish Study Group. Ann. Med., 25 (6): 545-549, 1993.

25- BERGER E., SAUNDERS N., WANG L. and FRIEDMAN J.N.: Sickle cell disease in children: Differentiating osteomyelitis from vaso-occlusive crisis. Arch. Pediatr. Adolesc. Med., 163 (3): 251-255, 2009.

26- DELGADO J., BEDOYA M.A., GREEN A.M., JARAMILLO D. and HO-FUNG V.: Utility of unenhanced fatsuppressed T1-weighted MRI in children with sickle cell 
disease can it differentiate bone infarcts from acute osteomyelitis? Pediatr. Radiol., 45 (13): 1981-1987, 2015.

27- OFFIAH A.C.: Acute osteomyelitis, septic arthritis and discitis: differences between neonates and older children. Eur. J. Radiol., 60 (2): 221-232, 2006.

28- METTLER F.A. Jr., HUDA W., YOSHIZUMI T.T. and MAHESH M.: Effective doses in radiology and diagnostic nuclear medicine: A catalog. Radiology, 248 (1): 254263,2008

29- MILLER R., BECK N.A., SAMPSON N.R., ZHU X., FLYNN J.M. and DRUMMOND D.: Imaging modalities for low back pain in children: A review of spondyloysis and undiagnosed mechanical back pain. J. Pediatr. Orthop., 33 (3): 282-88, 2013.
30- LEE Y.J, SADIGH S., MANKAD K., KAPSE N. and RAJESWARAN G.: The imaging of osteomyelitis. Quant. Imaging. Med. Surg., 6 (2): 184-198, 2016.

31- PELTOLA H. and PÄÄKKÖNEN M.: Acute osteomyelitis in children. N. Engl. J. Med., 370 (4): 352-360, 2014.

32- BROWNE L.P., GUILLERMAN R.P., ORTH RC., PATEL J., MASON E.O. and KAPLAN S.L.: Community-acquired staphylococcal musculoskeletal infection in infants and young children: Necessity of contrast-enhanced MRI for the diagnosis of growth cartilage involvement. AJR. Am. J. Roentgenol., 198 (1): 194-199, 2012.

33- DI POCE J., JBARA M.E. and BRENNER A.I.: Pediatric osteomyelitis: Scintigraphic case-based review. RadioGraphics, 32 (3): 865-878, 2012.

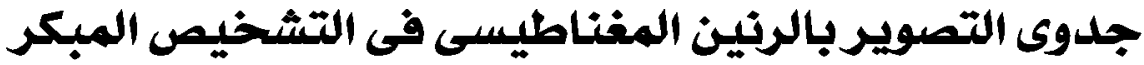

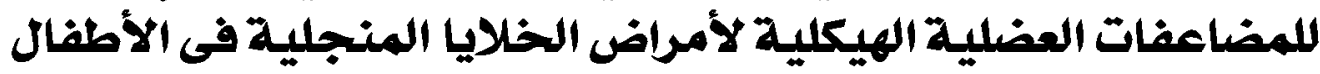

\author{
الهدف من العمل: تقييم جدوى التصوير بالرنين المغناطيسى فى الكشف المبكر عن المضاعفات العضلية الهيكلية لمرض الخلايا المنجلية \\ في الأطفال التى تهدف إلى التمييز بين إلتهاب العظم وجلطات العنين العظام.

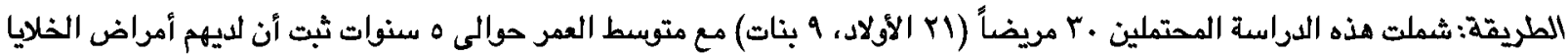 \\ المنجلية ويشتبه فى أن يكونوا مصابين بإلتهاب الفظم. خضع جميع المرضى للأثعة السينية وسلاسل مختلفة من التصوير بالرنين المغناطيسى.

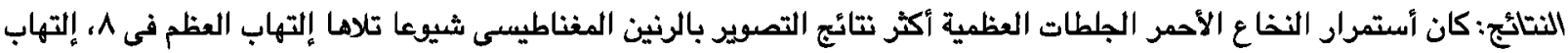

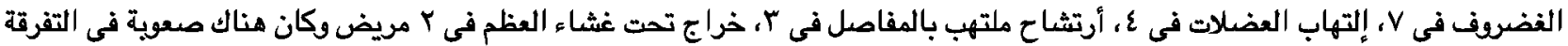 \\ بين إلتهاب العظم والجلطات العظمية. \\ الخلاصة: التصوير بالرنين المغناطيسى مفيد في التعرف المبكر على تشومات العضلات والعظام في أمراض الخلايا المنجلية في الأطفال.

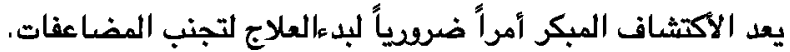

